\begin{tabular}{r|l|l|l}
$\begin{array}{c}\text { Case Reports in } \\
\text { Gastruenterology }\end{array}$ & $\begin{array}{l}\text { Case Rep Gastroenterol 2011;5:63-72 } \\
\text { DOI: 10.1159/000316635 }\end{array}$ & $\begin{array}{l}\text { Published online: } \\
\text { January 29, 2011 }\end{array}$ & $\begin{array}{l}\text { O 2011 S. Karger AG, Basel } \\
\text { ISSN 1662-0631 } \\
\text { www.karger.com/crg }\end{array}$ \\
\hline
\end{tabular}

This is an Open Access article licensed under the terms of the Creative Commons AttributionNonCommercial-NoDerivs 3.0 License (www.karger.com/OA-license), applicable to the online version of the article only. Distribution for non-commercial purposes only.

\title{
Elastography for Hepatic Fibrosis Severity in Chronic Hepatitis B or C
}

\author{
Maria-Vasiliki Papageorgiou ${ }^{a} \quad$ George V. Papatheodoridis ${ }^{a}$ \\ Spilios Manolakopoulos ${ }^{\mathrm{a}}$ Emmanuel Tsochatzis ${ }^{\mathrm{a}}$ \\ Hariklia Kranidiotia Georgia Kafiri ${ }^{\mathrm{b}}$ \\ Athanasios I. Archimandritis ${ }^{\mathrm{a}}$
}

and Department of Internal Medicine, Medical School of Athens University, and bDepartment of Pathology, 'Hippokration' General Hospital of Athens, Athens, Greece

\section{Key Words}

Transient elastography · Fibroscan · Surrogate markers · Liver biopsy · Chronic hepatitis · Liver fibrosis · Cirrhosis

\begin{abstract}
Aims: To assess the value of transient elastography for predicting significant fibrosis or cirrhosis in chronic hepatitis $\mathrm{B}$ or $\mathrm{C}(\mathrm{CHB}$ or $\mathrm{CHC})$ patients.

Methods: 75 patients (CHB: 45, CHC: 32) were included. All underwent elastography and liver biopsy concurrently. Biopsies were evaluated using Ishak's classification. Fibrosis was mild, moderate or severe/cirrhosis when scores were $0-1(n=30), 2-3(n=20), 4-6$ $(\mathrm{n}=25)$, respectively.

Results: Median liver stiffness values were higher in patients with severe fibrosis or cirrhosis than in those with moderate or mild fibrosis (14.8 vs. 6.4 vs. $5.3 \mathrm{kPa}, \mathrm{p}<0.001)$. The diagnostic accuracy of elastography for severe fibrosis and cirrhosis was excellent [area under the receiver operating characteristic (AUROC) curve 0.938 vs. 0.948], but it was not optimal for mild fibrosis (AUROC 0.78). Values of 7.5, 9.0 and $12 \mathrm{kPa}$ had a sensitivity and specificity for severe fibrosis/cirrhosis of 96,84 and $60 \%$, and 76, 90 and $94 \%$, respectively. The median stiffness value in cirrhotic patients (score 5-6) was 16.6 $\mathrm{kPa}$ (7.7-48). No differences in accuracy of elastography between CHB or CHC patients were found. Cutoff was $12.5 \mathrm{kPa}$ for cirrhosis; $10 / 75$ patients (13\%) were misclassified. Conclusion: Transient elastography has an excellent diagnostic accuracy for severe fibrosis and cirrhosis in $\mathrm{CHB}$ and $\mathrm{CHC}$, but the cutoffs need further evaluation.
\end{abstract}




\begin{tabular}{r|l|l|l}
$\begin{array}{r}\text { Case Reports in } \\
\text { Gastruanteriology }\end{array}$ & $\begin{array}{l}\text { Case Rep Gastroenterol 2011;5:63-72 } \\
\text { DOI: 10.1159/000316635 }\end{array}$ & $\begin{array}{l}\text { Published online: } \\
\text { January 29, 2011 }\end{array}$ & $\begin{array}{l}\text { O 2011 S. Karger AG, Basel } \\
\text { ISSN 1662-0631 } \\
\text { www.karger.com/crg }\end{array}$ \\
\hline
\end{tabular}

\section{Introduction}

Fibrosis is the final result of chronic liver diseases regardless of etiology. The extent of fibrosis is essential not only for the prognosis but also for the treatment of chronic liver diseases. Liver biopsy remains the gold standard for the assessment of liver fibrosis. However, it is an invasive procedure and not without risks. Moreover, liver histological lesions change with time, stressing the need for periodic assessment of liver histology by repeated liver biopsies, which increase the cost, give rise to questions concerning life quality and ethical issues, and are often refused by the patients. All these aspects together with the possibility of complications [1], sampling errors [2], and inter- and intra-pathologists variability [3] have stimulated the research for non-invasive markers of fibrosis.

Transient elastography is a new, non-invasive method that measures liver tissue stiffness. Transient elastography by Fibroscan samples a volume of approximately $4 \mathrm{~cm}^{3}$, which is more representative of liver tissue than a liver biopsy specimen. Measurements can usually be performed quickly and are highly reproducible, while they may be inaccurate or impossible in patients with obesity, ascites or narrow intercostal spaces [4]. Transient elastography has also been demonstrated to be a reliable tool for assessing fibrosis and cirrhosis mainly in patients with chronic hepatitis $\mathrm{C}(\mathrm{CHC})[5,6]$. Although there are some studies evaluating the accuracy of elastography in patients with chronic liver diseases of other etiologies $[7,8]$, more data are required in these settings, particularly in patients with chronic hepatitis $\mathrm{B}(\mathrm{CHB})$, who represent a large group of patients with chronic liver disease in many areas worldwide.

The purpose of this study was to assess the accuracy of liver stiffness measurement by elastography for the diagnosis of severe fibrosis and cirrhosis as estimated by liver biopsy in patients with $\mathrm{CHB}$ or $\mathrm{CHC}$.

\section{Materials and Methods}

\section{Patient Population}

We included 75 consecutive patients with chronic viral hepatitis (CHB: $\mathrm{n}=45$, CHC: $\mathrm{n}=32$ ) who underwent transient elastography and liver biopsy at the same time from July 2007 until October 2008. Patients with hepatitis B virus (HBV) and hepatitis $\mathrm{C}$ virus (HCV) coinfection, detectable antibodies against hepatitis delta virus (anti-HDV) or against human immunodeficiency virus (anti-HIV), other causes of liver injury (alcohol abuse, use of known hepatotoxic drugs, autoimmune hepatitis, metabolic or cholestatic liver diseases) and malignancy were excluded. No patient had decompensated liver disease (history or evidence of ascites, variceal bleeding, hepatic encephalopathy or jaundice). The diagnosis of $\mathrm{CHB}$ was made in cases who were HBsAg positive for at least 6 months, who had increased alanine aminotransferase (ALT) activity [ALT > upper limit of normal (ULN)] on at least two separate monthly determinations within the last 6 months and serum HBV DNA $>2,000 \mathrm{IU} / \mathrm{ml}$. The diagnosis of CHC was made in cases with detectable antibodies against HCV (anti-HCV) and HCV RNA in serum.

\section{Methods}

Data about weight and height on the liver biopsy day as well as about average alcohol consumption during the 5 years preceding the liver biopsy, smoking, concurrent diseases and treatment were recorded from all patients. Alcohol abuse was defined as a mean daily consumption of $>60 \mathrm{~g}$ of alcohol for male and $>40 \mathrm{~g}$ for female patients over the last 6 months. Full blood count including platelet count 


\begin{tabular}{r|l|l|l}
$\begin{array}{r}\text { Case Reports in } \\
\text { Gastruanteriology }\end{array}$ & $\begin{array}{l}\text { Case Rep Gastroenterol 2011;5:63-72 } \\
\text { DOI: 10.1159/000316635 }\end{array}$ & $\begin{array}{l}\text { Published online: } \\
\text { January 29, 2011 }\end{array}$ & $\begin{array}{l}\text { O 2011 S. Karger AG, Basel } \\
\text { ISSN 1662-0631 } \\
\text { www.karger.com/crg }\end{array}$ \\
\hline
\end{tabular}

(PLT), prothrombin time and liver function tests [ALT, aspartate aminotransferase (AST), alkaline phosphatase (ALP), gamma-glutamyl-transpeptidase (GGT)] were evaluated by commercially available assays in all patients on the liver biopsy day. Commercially available enzyme immunoassays were used for the detection of HBV markers (HBsAg, HBeAg, anti-HBe), anti-HCV and anti-HIV and commercially available polymerase chain reaction assays for the detection of serum HBV DNA and HCV RNA.

\section{Transient Elastography}

All transient elastographies were performed by one of two operators (M.-V.P., H.K.) and the result was considered reliable when the success rate (valid to total measurements) was $>60 \%$ and the interquartile range (IQR) $<30 \%$ of the final liver stiffness, as previously suggested by others [9].

\section{Liver Histology}

All 75 patients had an adequate biopsy specimen with a length of $\geq 1.5 \mathrm{~cm}$. All liver biopsies were evaluated by one blinded liver histopathologist (G.K.) and the histological changes of chronic hepatitis were classified according to the classification proposed by Ishak et al. [10]. The chronic hepatitis grading score $(0-18)$, which represents the necroinflammatory activity, was the sum of piecemeal necrosis score (0-4), confluent necrosis score (0-6), focal lytic necrosis, apoptosis and focal inflammation score (0-4) and portal inflammation score (0-4). The chronic hepatitis staging score $(0-6)$, which is referred to as the fibrosis score, was based on the degree and extent of fibrosis, architectural alterations and development of cirrhosis. Fibrosis score $0-1$ was considered as absence of fibrosis or mild fibrosis. Advanced staging or significant fibrosis was considered as a staging/fibrosis score of 4-6 and cirrhosis as a staging/fibrosis score of 5-6.

\section{Statistical Analysis}

All data were analyzed using the statistical package SPSS 15.0. Quantitative variables with normal distribution were expressed as mean values \pm standard deviation (SD) and those with abnormal distribution as median values (range). Statistical analysis was performed using t test or Mann-Whitney test for comparisons of quantitative variables between groups, Spearman's coefficient for correlations of quantitative variables and corrected $\chi^{2}$ method or two-tailed Fisher's exact test for qualitative data, when appropriate. Transient elastography was evaluated using the liver stiffness both as a quantitative and qualitative variable after having classified patients into groups according to their liver stiffness $(\leq 12.5$ or $>12.5 \mathrm{kPa}$ ) for prediction of cirrhosis. The accuracy of transient elastography for predicting no/mild fibrosis, significant fibrosis or cirrhosis was assessed by the area under the receiver operating characteristic (ROC) curve. A two-tailed $p$ value of $<0.05$ was considered to be statistically significant.

\section{Results}

The baseline characteristics of all patients are presented in table 1. Patients with $\mathrm{CHB}$ compared to those with $\mathrm{CHC}$ were more frequently males and had a higher mean value of liver stiffness. According to the stage of fibrosis, most (29/75 or 39\%) of our patients had no or mild fibrosis, while significant fibrosis or cirrhosis was observed in 25 (33\%) of the 75 patients. Patients with significant fibrosis or cirrhosis compared to those with moderate, compared to those with no or mild fibrosis were older (mean \pm SD age: $56 \pm 11$ vs. $50 \pm 14$ vs. $43 \pm 13$ years, $\mathrm{p}=0.003)$, had a relatively higher BMI ( $26 \pm 5$ vs. $26 \pm 2$ vs. $\left.24 \pm 3 \mathrm{~kg} / \mathrm{m}^{2}, \mathrm{p}=0.059\right)$, worse necroinflammatory activity ( $7 \pm 3$ vs. $5 \pm 2$ vs. $4 \pm 2, \mathrm{p}<$ $0.001)$, and greater liver stiffness $(16.8 \pm 9.5$ vs. $6.6 \pm 2.8$ vs. $5.8 \pm 2.2 \mathrm{kPa}, \mathrm{p}=<0.001)$.

Liver stiffness was found to be significantly associated with the fibrosis stage ( $\mathrm{p}<$ $0.001)$, but there was wide overlap in the values of liver stiffness among the different 


\begin{tabular}{r|l|l|l}
$\begin{array}{r}\text { Case Reports in } \\
\text { Gastruanteriology }\end{array}$ & $\begin{array}{l}\text { Case Rep Gastroenterol 2011;5:63-72 } \\
\text { DOI: 10.1159/000316635 }\end{array}$ & $\begin{array}{l}\text { Published online: } \\
\text { January 29, 2011 }\end{array}$ & $\begin{array}{l}\text { O 2011 S. Karger AG, Basel } \\
\text { ISSN 1662-0631 } \\
\text { www.karger.com/crg }\end{array}$ \\
\hline
\end{tabular}

stages of fibrosis (fig. 1). In particular, the mean (SD) liver stiffness $(\mathrm{kPa})$ was $5.8(2.2)$, $6.6(2.8), 11.3(5.0)$ and $19.4(5.0)$ in patients with fibrosis stage $0-1,2-3,4$ and 5-6, respectively $(\mathrm{p}<0.001)$.

Liver stiffness was found to have moderate accuracy for predicting absence of fibrosis (stage 0-1) (c-statistic: 0.784) without significant difference between patients with CHB or CHC. The accuracy of prediction for moderate fibrosis did not substantially change (c-statistic: 0.747 ) when only patients with elastography with IQR $<30 \%$ of liver stiffness were included.

On the contrary, liver stiffness was found to have excellent accuracy for predicting severe fibrosis (stage 4-6) (c-statistic: 0.926) in all patients as well as in patients with CHB (c-statistic: 0.902) or CHC (c-statistic: 0.952) (fig. 2). The accuracy of prediction for severe fibrosis did not change significantly (c-statistic: 0.940 ) when only patients with elastography with IQR $<30 \%$ of liver stiffness were included.

The accuracy of liver stiffness for predicting cirrhosis (stage 5-6) was also excellent (c-statistic: 0.948) without significant difference between patients with $\mathrm{CHB}$ or $\mathrm{CHC}$ (c-statistic: 0.930 vs. 0.960 ) (fig. 3). Again, there was no change in the accuracy of prediction for cirrhosis (c-statistic: 0.960 ) when only patients with elastography with IQR $<30 \%$ of liver stiffness were included.

When a widely proposed cutoff value of $12.5 \mathrm{kPa}$ for predicting cirrhosis was used, 10 (13\%) of the 75 patients were found to be misclassified (5 with cirrhosis overestimation, 5 with cirrhosis underestimation). Misclassified patients were older, more obese, under antiviral therapy and had a wider range of liver stiffness measurements (IQR $>30 \%$ ) (table 2). In our population, transient elastography underestimated $29.4 \%$ of cirrhotic patients. On the other hand, $8.6 \%$ of the patients were classified as cirrhotic by transient elastography, while no cirrhosis was observed according to the biopsy specimen.

\section{Discussion}

Chronic viral hepatitis is an important issue of public health worldwide, which is associated with increased morbidity and mortality. The main therapeutic goal for patients with chronic viral hepatitis is the prevention of cirrhosis-associated complications and hepatocellular carcinoma. Assessment of the degree of hepatic fibrosis is important not only to determine the prognosis of chronic liver disease but also to select patients for treatment and to monitor the success of treatment. Despite the significant progress in diagnosis and therapeutic intervention over the last decade, there is still a substantial proportion of patients that cannot be treated effectively [11]. Additionally, because of the high cost and the potential side effects of the anti-HCV agents and the unknown, perhaps indefinite, treatment duration of oral anti-HBV agents, therapy may often be recommended in patients with significant histological lesions or a high risk of worsening liver histology. Thus, staging is important for the estimation of prognosis and decision for therapeutic intervention.

Liver biopsy is currently the gold standard for the assessment of liver fibrosis. However, it is an invasive procedure associated with patient discomfort and occasionally with serious complications. In addition, the accuracy of the procedure is limited due to intra- and inter-observer variability and sampling errors [1-3]. Even when biopsy is 


\begin{tabular}{r|l|l|l}
$\begin{array}{r}\text { Case Reports in } \\
\text { Gastruenterology }\end{array}$ & $\begin{array}{l}\text { Case Rep Gastroenterol 2011;5:63-72 } \\
\text { DOI: 10.1159/000316635 }\end{array}$ & $\begin{array}{l}\text { Published online: } \\
\text { January 29, 2011 }\end{array}$ & $\begin{array}{l}\text { @ 2011 S. Karger AG, Basel } \\
\text { ISSN 1662-0631 } \\
\text { www.karger.com/crg }\end{array}$ \\
\hline
\end{tabular}

performed and interpreted by an expert, it has an error rate in disease staging of up to $20 \%$. Moreover, liver histological lesions change with time, stressing the need for periodic assessment of liver histology by repeated liver biopsies, which, however, increase the cost, give rise to questions concerning life quality and ethical issues and, most importantly, are often refused by the patients.

The limitations of percutaneous liver biopsy and particularly the difficulty in performing repeated procedures have increased the need for non-invasive means to assess liver histological lesions. Different approaches to estimate liver fibrosis non-invasively have been proposed, including indirect fibrosis tests based on routine liver function parameters, direct fibrosis tests based on extracellular matrix proteins and physical methods that estimate fibrosis by measuring liver stiffness.

Transient elastography by Fibroscan is a relatively new, easy to perform, and promising technique that estimates the degree of hepatic fibrosis by measuring liver stiffness [4]. Fibroscan samples a volume of approximately $4 \mathrm{~cm}^{3}$, which is more representative of the entire liver than a needle biopsy specimen. Measurements are quickly performed and are highly reproducible. Liver stiffness measurements range from 2.5 to $75 \mathrm{kPa}$.

In this study, liver stiffness values were found to be significantly associated with the extent of fibrosis, but there were significant overlaps in these values among patients with different histological stages (fig. 1). This finding is in accordance with the results of other studies [9], which also showed wide overlaps of liver stiffness values between adjacent stages of hepatic fibrosis, particularly for mild stages of fibrosis.

The area under ROC curve for the prediction of no or mild fibrosis was 0.784 and there was no liver stiffness value offering both sensitivity and specificity over 70\%. The accuracy of liver stiffness values for the prediction of severe fibrosis and cirrhosis was excellent with areas under ROC curves being $>0.90$ when $\mathrm{CHB}$ and $\mathrm{CHC}$ patients were analyzed together or separately. These findings are also in agreement with previous reports further supporting the excellent overall predictability of Fibroscan of the presence of advanced fibrosis or cirrhosis in patients with chronic viral hepatitis $[9,12]$. Despite the excellent results from the ROC curves analyses, however, it was impossible to identify very strong cutoff stiffness values in our patients. In particular, no stiffness value offered both sensitivity and specificity over $80 \%$ for the prediction of severe fibrosis or cirrhosis.

The stiffness cutoff values for cirrhosis have been reported to range from $10.3 \mathrm{kPa}$ in patients with CHB [13] to $17.3 \mathrm{kPa}$ in patients with cholestatic diseases [7], but the optimal cutoff value remains to be determined. Using the stiffness cutoff value of $12.5 \mathrm{kPa}$ proposed by Castera et al. [14] for the prediction of cirrhosis in patients with CHC, we examined the cases with discordance between transient elastography and liver biopsy findings. We found that $13 \%$ of our 75 patients were misclassified ( $7 \%$ in the study of Castera et al. [14]). In particular, cirrhosis was overestimated by Fibroscan in 5 and underestimated in another 5 cases. The 10 patients misclassified compared to patients correctly classified by elastography were older, under antiviral treatment and had more frequently an unreliable test (IQR $>30 \%$ of the median value [9]). The latter characteristic may be, at least partly, responsible for the relatively rarer misclassification rate in the study of Castera et al., in which only patients with IQR $<30 \%$ of the median stiffness values were included [14]. It should be noted, however, that many patients with elastographies considered to be unreliable (IQR $>30 \%$ of liver stiffness) were classified 


\begin{tabular}{r|l|l|l} 
Case Reports in & $\begin{array}{l}\text { Case Rep Gastroenterol 2011;5:63-72 } \\
\text { DOI: 10.1159/000316635 }\end{array}$ & $\begin{array}{l}\text { Published online: } \\
\text { January 29, 2011 }\end{array}$ & $\begin{array}{l}\text { ○ 2011 S. Karger AG, Basel } \\
\text { ISSN 1662-0631 } \\
\text { www.karger.com/crg }\end{array}$ \\
\hline
\end{tabular}

correctly according to their liver stiffness measurements, and therefore the exclusion of these cases did not affect the overall accuracy of prediction of elastography in our study.

In conclusion, our data further support that liver stiffness measurements by transient elastography are strongly associated with the extent of fibrosis $[9,12]$. Fibroscan's diagnostic accuracy for the presence of advanced fibrosis or cirrhosis in patients with chronic viral hepatitis was found to be excellent (AUROC $>0.90$ ). We should keep in mind that, as recently suggested by Mehta et al. [15], even in the best scenario where liver biopsy accuracy is highest, the calculated AUROC would be 0.90 . However, transient elastography cannot replace liver biopsy yet, particularly in the initial evaluation of patients with chronic viral hepatitis, mainly because it may misclassify approximately $10 \%$ of cases for the presence of cirrhosis [14]. Moreover, liver biopsy offers additional information on all types of histological lesions and not only on liver fibrosis. The optimal cutoff of liver stiffness values for the prediction of cirrhosis and whether this may be specifically defined for each type of chronic liver disease remains to be determined [16]. In our study, there was no difference in the prognostic accuracy of elastography for the extent of fibrosis between patients with $\mathrm{CHB}$ and $\mathrm{CHC}$. Since transient elastography is easy to perform and has excellent patient acceptance, it seems to be very useful for monitoring changes of fibrosis in the individual patient. It should be noted, however, that the potential effect of treatment on the accuracy of elastography has not been adequately studied to date and, therefore, more data in patients under therapy should be obtained before the wide establishment of such a use of elastography in routine clinical practice.

Table 1. Baseline characteristics of 75 patients with $\mathrm{CHB}$ or $\mathrm{CHC}$

\begin{tabular}{lcccc}
\hline & $\begin{array}{l}\text { CHB } \\
(\mathrm{n}=43)\end{array}$ & $\begin{array}{l}\text { CHC } \\
(\mathrm{n}=32)\end{array}$ & $\begin{array}{l}\text { Total } \\
(\mathrm{n}=75)\end{array}$ & $\mathrm{p}$ \\
\hline Sex, males (\%) & $33(77)$ & $16(50)$ & $49(65)$ & 0.017 \\
Age, years & $48 \pm 14$ & $51 \pm 13$ & $49 \pm 14$ & 0.419 \\
Height, $\mathrm{m}$ & $1.7 \pm 0.1$ & $1.7 \pm 0.1$ & $1.7 \pm 0.1$ & 0.836 \\
Weight, kg & $72.8 \pm 11.7$ & $72.6 \pm 13.6$ & $72.7 \pm 12.4$ & 0.930 \\
BMI, kg/m & $25.2 \pm 2.7$ & $25.4 \pm 4.3$ & $25.3 \pm 3.5$ & 0.851 \\
Other diseases, $\mathrm{n}(\%)$ & $8(19)$ & $8(25)$ & $16(21)$ & 0.357 \\
Alcohol, $\mathrm{n}(\%)$ & $6(14)$ & $4(12)$ & $10(13)$ & 0.259 \\
Smoking, $\mathrm{n}(\%)$ & $16(37)$ & $16(50)$ & $32(43)$ & 0.135 \\
Under therapy, $\mathrm{n}(\%)$ & $19(44)$ & $14(44)$ & $33(44)$ & 0.882 \\
Necroinflammation & $5 \pm 2$ & $5 \pm 2$ & $5 \pm 2$ & 0.443 \\
Fibrosis & $3 \pm 2$ & $3 \pm 2$ & $3 \pm 2$ & 0.369 \\
Liver stiffness, kPa & $7.7 \pm 5.0$ & $12.3 \pm 9.7$ & $9.7 \pm 7.7$ & 0.009 \\
\hline \multicolumn{7}{c}{ BMI = Body mass index. } & & & \\
\hline
\end{tabular}




\begin{tabular}{r|l|l|l} 
Case Reports in & $\begin{array}{l}\text { Case Rep Gastroenterol 2011;5:63-72 } \\
\text { DOI: } 10.1159 / 000316635\end{array}$ & $\begin{array}{l}\text { Published online: } \\
\text { January 29, 2011 }\end{array}$ & $\begin{array}{l}\text { @ 2011 S. Karger AG, Basel } \\
\text { ISSN 1662-0631 } \\
\text { www.karger.com/crg }\end{array}$ \\
\hline
\end{tabular}

Table 2. Characteristics of correctly and falsely classified patients in relation to the presence of cirrhosis and the stiffness cutoff of $12.5 \mathrm{kPa}$ at transient elastography

\begin{tabular}{lccc}
\hline & $\begin{array}{l}\text { Correct classification } \\
(\mathrm{n}=65)\end{array}$ & $\begin{array}{l}\text { Wrong classification } \\
(\mathrm{n}=10)\end{array}$ & $\mathrm{p}$ \\
\hline Sex, males (\%) & $42(65)$ & $7(70)$ & 0.739 \\
Age, years & $47 \pm 13$ & $63 \pm 11$ & 0.001 \\
BMI, kg/m & $25.3 \pm 3.5$ & $25.1 \pm 3.6$ & 0.844 \\
Type of CH, n (\%) & & $6(60)$ & \\
$\quad$ CHB & $37(57)$ & $4(40)$ & 0.855 \\
CHC & $28(43)$ & $9(90)$ & 0.001 \\
Under therapy, n (\%) & $24(37)$ & $4(40)$ & 0.140 \\
Other diseases, n (\%) & $12(18)$ & $6(60)$ & 0.075 \\
Drugs, n (\%) & $20(31)$ & $2(20)$ & 0.713 \\
Alcohol, $\mathrm{n}(\%)$ & $8(12)$ & $2(20)$ & 0.027 \\
Smoking, $\mathrm{n}(\%)$ & $30(46)$ & $5(50)$ & 0.006 \\
IQR/stiffness $(>30 \%)$ & $56(86)$ & & \\
\hline
\end{tabular}

$\mathrm{BMI}=$ Body mass index; IQR = interquartile range.

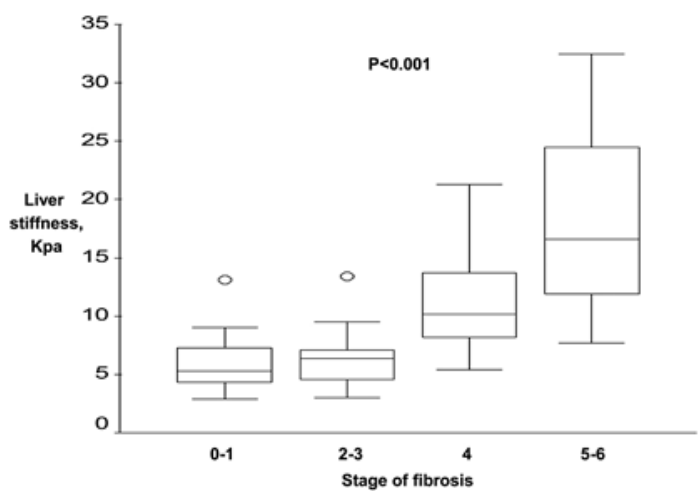

Fig. 1. Liver stiffness values by elastography for each stage of fibrosis. Box and whisker plots express median values and interquartile and overall ranges. Liver stiffness values are significantly higher in more severe stages of fibrosis $(\mathrm{p}<0.001)$, but there are significant overlaps among the different fibrosis stages. 

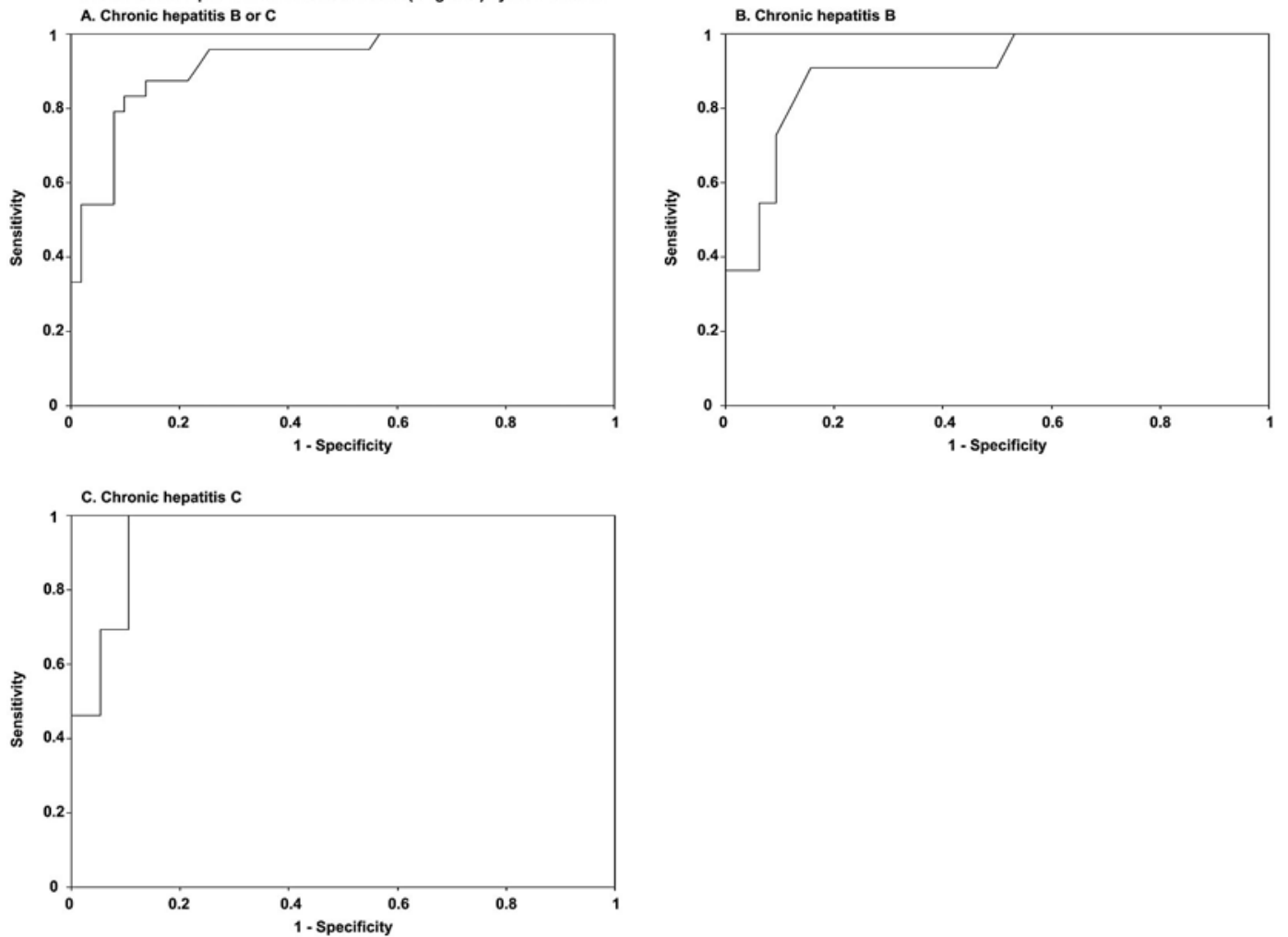

Fig. 2. ROC curve for the prediction of severe fibrosis (stage 4-6) by liver elastography. Liver stiffness values have excellent overall accuracy for predicting severe fibrosis (c-statistic: 0.926$)$ in all patients with $\mathrm{CHB}$ or $\mathrm{CHC}(\mathbf{A})$ as well as in patients with $\mathrm{CHB}$ only (c-statistic: 0.902) (B) or patients with CHC only (c-statistic: 0.952) (C). 


\begin{tabular}{|c|c|c|c|}
\hline $\begin{array}{l}\text { Case Reports in } \\
\text { tin }\end{array}$ & $\begin{array}{l}\text { Case Rep Gastroenterol 2011;5:63-72 } \\
\text { DOI: } 10.1159 / 000316635\end{array}$ & \begin{tabular}{|l|} 
Published online: \\
January 29, 2011
\end{tabular} & $\begin{array}{l}\text { @ } 2011 \text { S. Karger AG, Basel } \\
\text { ISSN 1662-0631 } \\
\text { www.karger.com/crg }\end{array}$ \\
\hline
\end{tabular}
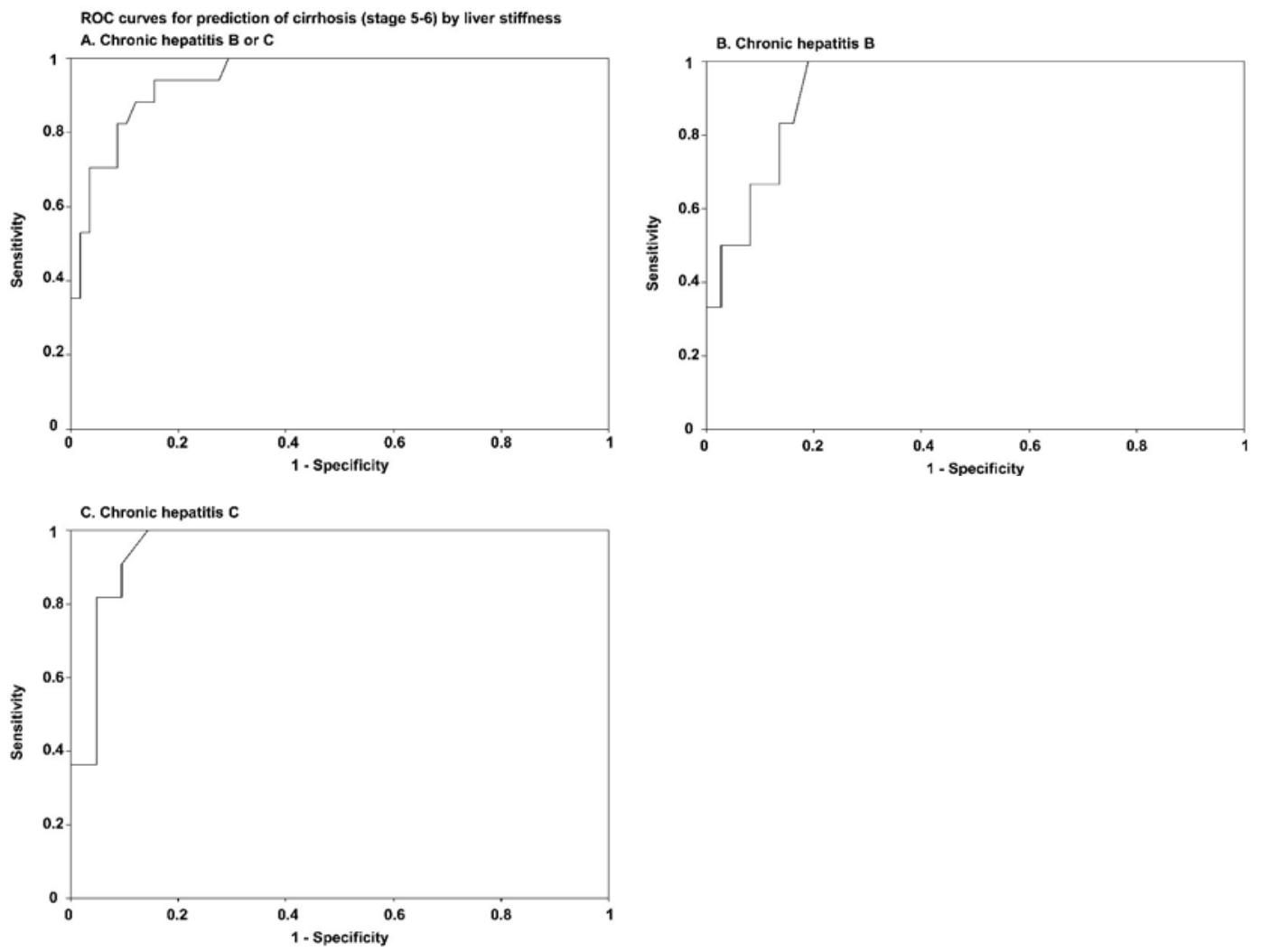

Fig. 3. ROC curve for the prediction of cirrhosis (stage 5-6) by liver elastography. The accuracy of liver stiffness for predicting cirrhosis is excellent in all patients with CHB or CHC (c-statistic: 0.948) (A) as well as in patients with $\mathrm{CHB}$ only (c-statistic: 0.930$)($ B) or patients with $\mathrm{CHC}$ only (c-statistic: 0.960$)$ (C).

\section{References}

1 Cadranel JF, Rufat P, Degos F: Practices of liver biopsy in France: results of a prospective nationwide survey. For the Group of Epidemiology of the French Association for the Study of the Liver (AFEF). Hepatology 2000;32:477-481.

2 Bedossa P, Dargere D, Paradis V: Sampling variability of liver fibrosis in chronic hepatitis C. Hepatology 2003;38:1449-1457.

3 Rousselet MC, Michalak S, Dupre F, et al: Sources of variability in histological scoring of chronic viral hepatitis. Hepatology 2005;41:257-264.

4 Stauber RE, Lackner C: Noninvasive diagnosis of hepatic fibrosis in chronic hepatitis C. World J Gastroenterol 2007;13:4287-4294.

-5 Castera L, Vergniol J, Foucher J, et al: Prospective comparison of transient elastography, Fibrotest, APRI, and liver biopsy for the assessment of fibrosis in chronic hepatitis C. Gastroenterology 2005;128:343-345.

6 Lucidarme D, Foucher J, Le Bail B, et al: Factors of accuracy of transient elastography (Fibroscan) for the diagnosis of liver fibrosis in chronic hepatitis C. Hepatology 2009;49:1083-1089.

7 Corpechot C, El Naggar A, Poujol-Robert A, et al: Assessment of biliary fibrosis by transient elastography in patients with PBC and PSC. Hepatology 2006;43:1118-1124.

8 Foucher J, Chanteloup E, Vergniol J, et al: Diagnosis of cirrhosis by transient elastography (FibroScan): a prospective study. Gut 2006;55:403-408.

-9 Castera L, Forns X, Alberti A: Non-invasive evaluation of liver fibrosis using transient elastography. J Hepatol 2008; $48: 835-847$. 
10 Ishak K, Baptista A, Bianchi L, et al: Histological grading and staging of chronic hepatitis. J Hepatol 1995;22:696-699.

11 Papatheodoridis GV, Hadziyannis SJ: Review article: current management of chronic hepatitis B. Aliment Pharmacol Ther 2004;19:25-37.

12 Marcellin P, Ziol M, Bedossa P, et al: Non-invasive assessment of liver fibrosis by stiffness measurement in patients with chronic hepatitis B. Liver Int 2009;29:242-247.

13 Coco B, Oliveri F, Maina AM, et al: Transient elastography: a new surrogate marker of liver fibrosis influenced by major changes of transaminases. J Viral Hepat 2007;14:360-369.

14 Castera L, Le Bail B, Roudot-Thoraval F, et al: Early detection in routine clinical practice of cirrhosis and oesophageal varices in chronic hepatitis C: comparison of transient elastography (FibroScan) with standard laboratory tests and non-invasive scores. J Hepatol 2009;50:59-68.

15 Mehta SH, Lau B, Afdhal NH, Thomas DL: Exceeding the limits of liver histology markers. J Hepatol 2009;50:36-41.

16 Ganne-Carrié N, Ziol M, de Ledinghen V, et al: Accuracy of liver stiffness measurement for the diagnosis of cirrhosis in patients with chronic liver diseases. Hepatology 2006;44:1511-1517. 